\title{
El papel del archivero frente a la Ley 39/2015: el documento electrónico y su implantación en una universidad: planificación, ejecución y herramientas
}

\section{Raül Rabionet i Janssen}

AGTIC Consulting S. L.

\section{Resumen}

La Ley 39/2015, de 1 de octubre, de Procedimiento Administrativo Común de las Administraciones Públicas, introduce un cambio de paradigma al imponer el documento electrónico como único soporte válido de la actuación administrativa. En este contexto, las universidades públicas tienen que planificar una nueva manera de trabajar, centrada en la tramitación de expedientes electrónicos y en la aplicación de los procesos de gestión documental en dicho soporte. Para que este modelo de trabajo sea sostenible a medio plazo, se requiere una planificación corporativa de los nuevos procedimientos y herramientas y el uso de soluciones transversales, en particular para el archivado de la documentación electrónica. Así, el rol del archivero cambia sustancialmente, ya que debe participar en la definición de los criterios, de tal manera que sus recomendaciones se apliquen en el momento en que la documentación se genera, y no solamente cuando se almacena. Trabajando conjuntamente con los responsables tecnológicos, jurídicos y organizativos, podrán definir las metodologías de trabajo que permitirán sacar el máximo beneficio, en términos de eficiencia y automatización de procesos, a estas nuevas herramientas.

Palabras clave: Documento electrónico; Expediente electrónico; Modelo de gestión documental; Política de gestión documental 
Cita recomendada: Rabionet i Janssen, R. (2018). El papel del archivero frente a la Ley 39/2015: el documento electrónico y su implantación en una universidad: planificación, ejecución y herramientas. En El archivo electrónico en la administración digital: 23 Jornadas de Archivos Universitarios, 21-23 de junio de 2017, A Coruña (pp. 93-100).

DOI capítulo: https://doi.org/10.17979/spudc.9788497496803.093

DOI libro: https://doi.org/10.17979/spudc.9788497496803

En la última década, la Administración Pública española ha dado importantes pasos para cambiar su modelo de gestión con el uso intensivo de las tecnologías de la información, mediante cambios legislativos y el despliegue de plataformas y herramientas para la gestión electrónica de la actividad administrativa, promovidas por la administración central y por entes especializados en facilitar este tipo de soluciones.

La Ley 11/2007, de 22 de junio, de Acceso Electrónico de los Ciudadanos a los Servicios Públicos, estableció las principales instituciones jurídicas que permiten una gestión electrónica del procedimiento administrativo, como son la sede electrónica, el registro electrónico y la notificación electrónica. Esta ley fue generalmente conocida como Ley de administración electrónica, pero en la práctica se interpretó y aplicó como una Ley de administración telemática, es decir, la mayor parte de las administraciones la desplegaron creando los mecanismos necesarios para poderse relacionar telemáticamente con el ciudadano, pero prestando poca atención al cambio de sus procesos internos.

Desde el punto de vista archivístico se han desarrollado múltiples estudios que avalan los ahorros en eficiencia y los beneficios organizativos en cuanto a agilidad de la tramitación, accesibilidad y 
seguridad de la información, resultantes de aplicar modelos de gestión basados en documentos electrónicos. La Ley 11/2007 introducía conceptos como el de expediente administrativo electrónico, pero en definitiva no obligaba a su utilización $\mathrm{y}$, por tanto, tuvo un impacto limitado en este sentido.

Cabe decir que el desarrollo normativo que despliega la Ley 11/2007 y, en concreto, el Esquema Nacional de Interoperabilidad y las Normas Técnicas que lo desarrollan, sí definen un entorno de actuación administrativa en el que toda la documentación es electrónica. A partir de estos desarrollos las administraciones más punteras en esta materia, como la Agencia Estatal de Administración Tributaria (AEAT), han llegado al punto de gestionar mucha de su actividad de manera enteramente electrónica.

La Ley 39/2015, de 1 de octubre, de Procedimiento Administrativo Común de las Administraciones Públicas, construye sobre el modelo definido previamente, pero da el impulso final al concepto de expediente electrónico, al establecer (artículo 26) que la actuación administrativa se soporta en documentos electrónicos. Esta obligación entró en vigor el 2 de octubre de 2016. El plazo de vacatio legis de un año podría considerarse breve para un cambio tan profundo, pero hay que tener en cuenta que el legislador parte de la idea de que hemos tenido ocho años para cumplir con la Ley 11/2007, para la cual el documento y expediente electrónicos ya eran elementos necesarios, si bien no excluyentes.

El hecho es que hemos tenido que aceptar que buena parte de la administración pública, también en el ámbito universitario, no hizo todos los esfuerzos necesarios para dar cumplimiento a la Ley 11/2007, y por ello muchos han quedado en una situación difícil con el más reciente cambio legal. La sustitución de la tramitación administrativa tradicional, 
basada en el papel, por una basada en documentos electrónicos, no se resuelve simplemente con el desarrollo de herramientas tecnológicas, sino que requiere de un profundo cambio organizativo que se despliega en cuatro niveles: a parte de las soluciones tecnológicas, se requiere el desarrollo de instrumentos archivísticos y modelos de gestión documental, se requiere un replanteamiento de los procedimientos y metodologías de trabajo y también, por último, la actualización de la normativa interna para dar cobertura a las nuevas herramientas.

Lo que está ocurriendo en muchas organizaciones, también en el ámbito universitario, es que se está llevando a cabo un despliegue apedazado de este cambio de paradigma: se están resolviendo las necesidades a medida que surgen, sin una visión transversal ni una planificación del cambio a nivel corporativo.

De esta manera, es frecuente encontrar herramientas de firma electrónica o sistemas de soporte a la tramitación, que se usan solamente para algunos procesos o de manera aislada en algunos departamentos, pero es poco común el uso eficaz de gestores documentales o de los servicios de interoperabilidad. En muchas administraciones se están produciendo documentos electrónicos sin que exista un plan sobre cómo se van a almacenar y preservar esos documentos en un sistema de archivo seguro.

La principal carencia a la que se enfrentan muchas administraciones es la ausencia de un modelo corporativo de gestión de los documentos electrónicos. Incluso aquellas que, en cumplimiento de la norma técnica de interoperabilidad correspondiente, se han dotado de una política de gestión de documentos electrónicos, lo han hecho desde un punto de vista programático, pero sin definir en concreto cómo aplican los distintos procesos documentales a su documentación electrónica. 
Un Modelo de Gestión de Documentos Electrónicos (MGDE) está formado básicamente por un conjunto de políticas que establecen las normas que se tienen que cumplir en toda la organización a la hora de crear, gestionar y conservar a lo largo del tiempo un documento o expediente electrónico. Es una herramienta dinámica, que tiene que ser definida con la colaboración de los principales agentes de la universidad y evoluciona conforme lo hacen la legislación y la tecnología.

El hecho de no disponer de un MGDE conlleva múltiples riesgos para la universidad:

- pérdida de la validez del documento electrónico, al no existir procesos para la preservación de las firmas electrónicas;

- dispersión y falta de integración de las soluciones tecnológicas;

- crecimiento desmedido del volumen almacenado;

- alta complejidad para gestionar todo el ciclo de vida de la documentación (su almacenamiento, transferencia, eliminación...);

- pérdida de las ventajas que supone la gestión de documentos y expedientes electrónicos, como la reducción de tiempo y de costes o la automatización de procesos;

- incremento de tareas sin valor añadido, como la gestión manual de los documentos electrónicos, el traslado manual de una herramienta a otra, etc.;

- ausencia de herramientas de interoperabilidad o intraoperabilidad;

- imposibilidad de preservar los documentos y expedientes electrónicos; y

- en definitiva, frustración para los usuarios ante las dificultades del nuevo modelo. 
Es fundamental comprender que la elaboración de un MGED debe ser transversal, contar con la involucración de las áreas principales y prever su impacto en el conjunto de la universidad. Así pues, además del servicio de archivo, que es vital a la hora de definir el modelo, será necesario la intervención de los servicios de informática, de responsables de organización y de la secretaría general o la asesoría jurídica (Figura 1).

Para garantizar su flexibilidad y perdurabilidad en el tiempo, conviene ver el Modelo de Gestión de Documentos Electrónicos como un conjunto de instrumentos o instrucciones internas, desplegados en forma de pirámide, cuya cúspide es la política de gestión documental, cuya vocación es de una larga duración, pero que se despliega en una serie de modelos y directrices sobre el ciclo de vida de los documentos, los procesos documentales (descripción, clasificación, acceso, preservación...) y la arquitectura tecnológica.

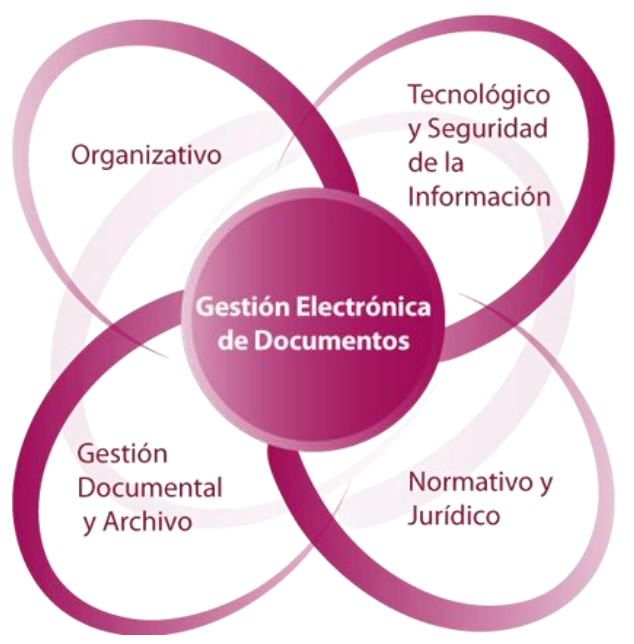

Figura 1. Ámbitos a involucrar en la definición del modelo 
Para hacernos una idea más aproximada, el MGDE debe dar respuesta a cuestiones como: qué formatos documentales se tienen que usar, qué formatos de firma, si queremos un modelo docucéntrico o datacéntrico, qué metadatos son necesarios y cómo se tienen que implementar en el gestor documental, cómo implementar el cuadro de clasificación en el gestor documental, cómo gestionar expedientes híbridos, o cómo generar el índice de los expedientes electrónicos.

Finalmente, el documento y el expediente electrónico implican un gran cambio en funciones que hasta ahora han estado atribuidas a los archivos. Algunas de ellas permanecerán, otras muchas son o serán nuevas y suponen una gran oportunidad para la profesión. Por ejemplo:

- ser el impulsor de la elaboración del MGDE y de la política de gestión del documento y expediente electrónico;

- integrarse en la comisión de gestión documental responsable de la elaboración, mantenimiento y cumplimiento del MGDE y de la política;

- integrarse en la comisión de seguridad;

- ser el responsable funcional de, como mínimo:

○ el gestor documental,

- los instrumentos archivísticos aplicados y

- el archivo electrónico único;

- ser miembro de los grupos de trabajo para la simplificación administrativa, por el importante papel que desempeña el documento electrónico en ella;

- ser el responsable de los expedientes en las fases semiactiva e histórica; 
- ser el responsable de los procesos de migración de formatos, para garantizar la preservación; y

- ser el responsable de los procesos de auditoría del sistema de gestión documental.

AGTIC Consulting SL, en colaboración con la Oficina de Cooperación Universitaria, está ofreciendo a las Universidades un modelo de proyecto de consultoría para abordar este proceso de cambio de manera organizada y establecer los objetivos de desarrollo e implementación de un modelo de gestión documental corporativo. Estos proyectos se construyen en tres fases, tal como se ve en la imagen siguiente, aunque los objetivos concretos se pueden personalizar en función de las necesidades de cada institución.

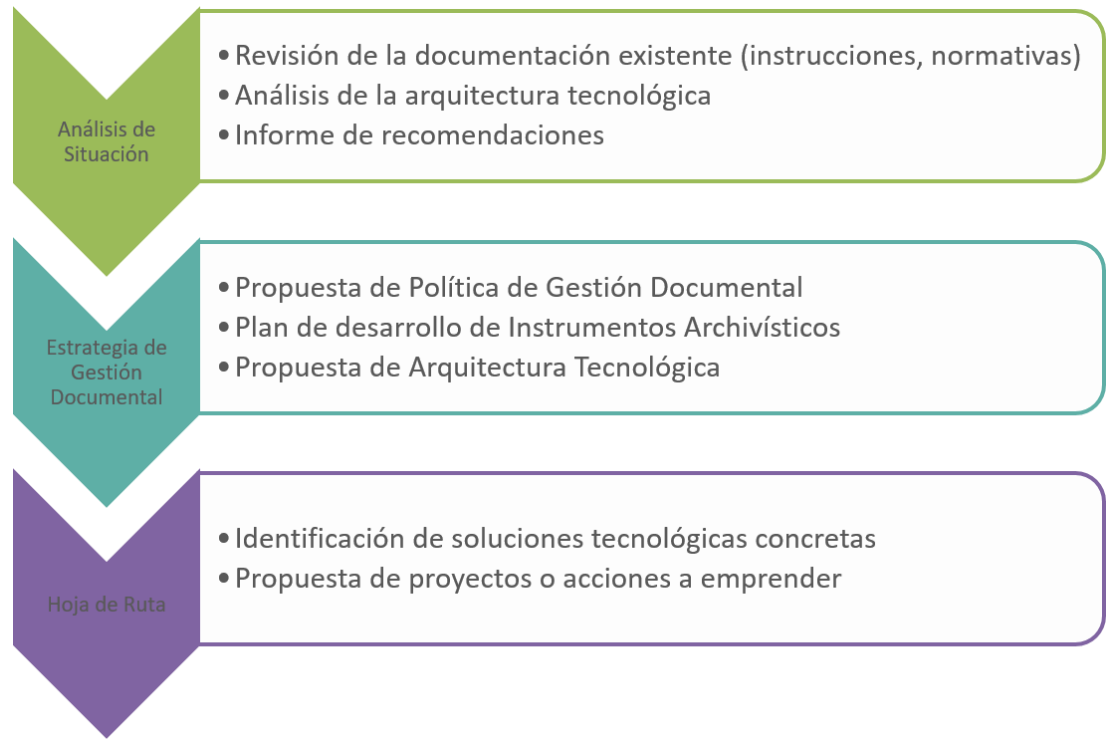

Figura 2. Fases clave del proyecto de consultoría 